Case Report

\section{First trimester growth delay: An early marker of triploidy}

\section{Sydney M Thayer ${ }^{1 *}$, Rachel A Pilliod ${ }^{1}$, Emmanuelle Pare ${ }^{1}$, Amber Vandehey ${ }^{1,2}$, Hannah Raszka ${ }^{1}$, Kelly Thomas ${ }^{1,2}$ and Rinathia Hachmon ${ }^{1}$}

'Oregon Health \& Science University, 3181 SW Sam Jackson Park Road, Portland, Oregon 97239, USA

${ }^{2}$ Tuality Community Hospital, 335 SE 8th Avenue, Hillsboro, Oregon 97123, USA

\section{More Information \\ *Address for Correspondence: Sydney M Thayer MD, Oregon Health \& Science University, 3181 SW Sam Jackson Park Road, Portland, Oregon 97239, USA, Tel: +503-418-4500; \\ Email: thayers@ohsu.edu}

Submitted: 14 November 2019

Approved: 20 November 2019

Published: 21 November 2019

How to cite this article: Thayer SM, Pilliod RA, Pare E, Vandehey A, Raszka H, et al. First trimester growth delay: An early marker of triploidy. Clin J Obstet Gynaecol. 2019; 2: 119-121.

DOI: dx.doi.org/10.29328/journal.cjog.1001032 ORCiD: orcid.org/0000-0003-4726-345X

Copyright: @ 2019 Thayer SM, et al. This is an open access article distributed under the Creative Commons Attribution License, which permits unrestricted use, distribution, and reproduction in any medium, provided the original work is properly cited.

(W) Check for updates

delay. Management options were offered. The patient elected to proceed with chorionic villus sampling (CVS) the following day. The fetal karyotype by CVS resulted in triploidy 69XXX.

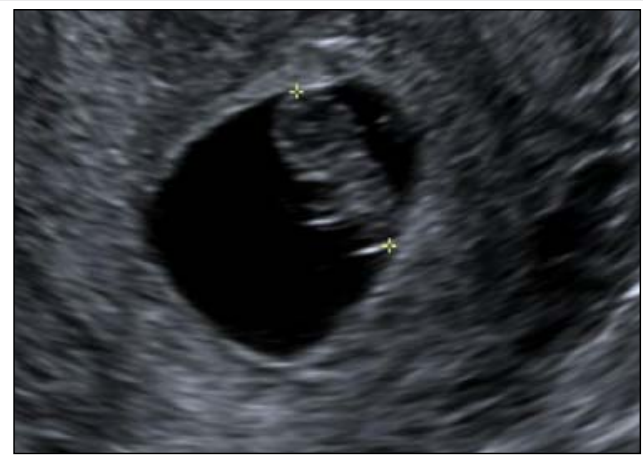

Figure 1: CRL at $7+4$ weeks by US and $9+0$ weeks by LMP.

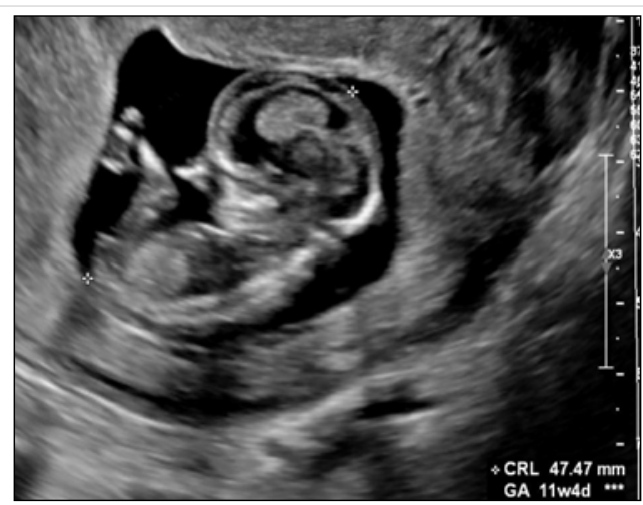

Figure 2: CRL at $13+1$ weeks by 7 week US and $14+4$ weeks by LMP 


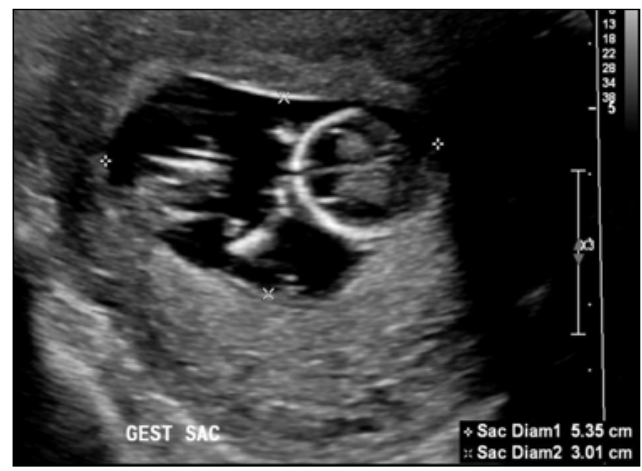

Figure 3: Averaged GS at $13+1$ weeks by 7 week US and $14+4$ weeks by LMP.

By $15+1$ weeks by first ultrasound dating, repeat ultrasound demonstrated a two vessel umbilical cord, absent right kidney, and a left ventricle echogenic mass. The stomach not visualized. The abdominal circumference and femur length measured less than the $5^{\text {th }}$ percentile. Given the poor fetal prognosis and maternal risk associated with triploidy, the patient elected to proceed with pregnancy termination.

\section{Discussion}

Fetal growth restriction is associated with multiple chromosomal abnormalities. In chromosomally normal fetuses, growth should increase exponentially with fetal gestational age [1]. While early markers of aneuploidy exist, first trimester identification of triploidy is rare due to challenges recognizing both subtle growth differences not attributed to gestational age dating and anatomic abnormalities early in development.

Phenotypic expression of triploidy often includes growth delay and organogenesis abnormalities. While no anomaly is considered pathognomonic for triploidy, bilateral cranial ventriculomegaly, cardiac anomalies, oligohydramnios and micrognathia are often noted [2].

Ultrasonographic examination can show hypoechoic areas within an enlarged placenta, and maternal serum analytes are often abnormal [3]. Even in the setting of a normal appearing placenta, a review of 70 second trimester pregnancies affected by triploidy found that each fetus had at least one growth measurement below the normal range [4]. The diagnosis of triploidy generally involves the combination of fetal growth and anatomy abnormalities, maternal serum analyte screening and placental characterization. Generally, these anomalies are not seen until the mid-second trimester.

First and early second trimester identification of triploidy is challenging. While clear first trimester anatomic differences are often absent, increased NT has shown association with triploidy in multiple studies and has been identified in up to 66 percent of triploid fetuses [4,5]. However, fetal growth restriction is the most common ultrasonographic feature of triploidy [3]. In a longitudinal study of five fetuses between 11 and 14 weeks, Salomon, et al. [6], established that gestational age-based cephalic and abdominal biometry was inferior to
CRL-based biometry in the diagnosis of triploidy, and that CRLbased biometry was able to demonstrate early asymmetric growth delay [6]. In fact, the fetal CRL was noted to be less than $5^{\text {th }}$ percentile in $62.5 \%$ of cases of triploidy identified in Jauniaux, et al. [7]. These findings are mostly seen in the second trimester.

Kuhn, et al. [1], found that CRL for triploidy fetuses in the first trimester appeared to be normal, though the number of triploid cases was too small to show significance [1]. Benacerraf is the first and only to date to report a case of fetal triploidy diagnosed in the first trimester solely based on growth restriction [8]. This diagnosis was confirmed with amniocentesis. In the case presented, we believe the fetal growth restriction was manifested at the viability ultrasound (9+0 weeks by LMP) when the gestational age was changed to a CRL-based measurement, and that her LMP was an accurate date to base the gestational age. The second growth discordancy was found at $13+1$ weeks despite the changed dating - most likely attributed to the slow rate of growth seen in triploidy - which raised the suspicion that the fetus was abnormal.

This case is of triploidy suspected in the first trimester by fetal growth delay which prompted CVS and early diagnosis. Suspicion was present despite the fetus meeting other developmental milestones and in the absence of fetal or placental anatomic differences. It is the first case of our knowledge to demonstrate confirmed triploidy by CVS following suspicion based only upon first trimester growth delay.

Discordancy between gestational age determined by LMP and CRL is common in the first trimester. In most cases, this discordance will lead to a change in gestational age to ultrasound dating due to LMP ambiguity. However, in cases when early ultrasound dating is not congruent with a certain LMP, follow up with repeat first trimester ultrasound for growth and early anatomy survey should be considered to address possible early growth delay. In some cases particularly when early growth restriction is persistent - it may be an early sign of an abnormal fetus that warrants further evaluation. Not every case of first trimester CRL discordancy is due to dating discrepancy and one of our goals in this case report is to increase the clinician awareness of this possibility. This case also emphasizes how early first trimester ultrasound together with late first trimester/early second trimester ultrasound may aid in earlier diagnosis of abnormal fetuses. Practitioners should consider triploidy when persistent early growth delay is appreciated, and appropriate counseling regarding genetic testing options is advised. Discussion about invasive diagnostic testing should take into consideration clinical suspicion for fetal anomalies and should be individualized to the patient after thorough discussion of risks and benefits. 


\section{Summary}

1. First trimester prenatal ultrasonography is an opportunity for early identification of fetal structural and growth abnormalities.

2. When early and persistent growth delay is present, practitioners should consider triploidy as a potential anomaly. Appropriate counseling and genetic testing options should be offered after discussion of potential risks and benefits.

\section{References}

1. Kuhn $\mathrm{P}$, de Lourdes Brizot M, Pandya PP, Snijder RJ, Nicholaides $\mathrm{KH}$ Crown-rump length in chromosomally abnormal fetuses at 10 to 13 weeks' gestation. Am J Obstet Gynecol. 1995; 172: 32-35.

PubMed: https://www.ncbi.nlm.nih.gov/pubmed/7847557

2. Pircon RA, Porto $M$, Towers CV, Crade $M$, Gocke SE. Ultrasound Findings in Pregnancies Complicated by Fetal Triploidy. J Ultrasound Med. 1989; 8: 507-511.

PubMed: https://www.ncbi.nlm.nih.gov/pubmed/2674473
3. Crane JP, Beaver HA, Cheung SW. Antenatal Ultrasound Findings in Fetal Triploidy Syndrome. J Ultrasound Med. 1985; 4: 519-524. PubMed: https://www.ncbi.nlm.nih.gov/pubmed/3903185

4. Pandya PP, Kondylois A, Hilbert L, Snijders RJ, Nicholaides KH. Chromosomal defects and outcome in 1015 fetuses with increased nuchal translucency. Ultrasound Obstet Gynecol. 1995; 5: 15-19. PubMed: https://www.ncbi.nlm.nih.gov/pubmed/7850583

5. Spencer K, Liao AW, Skentou H, Cicero S, Nicolaides KH. Screening for triploidy by fetal nuchal translucency and maternal serum free beta-hCG andPAPP-Aat 10-14weeksofgestation.PrenatDiagno.2000;20:495-499. PubMed: https://www.ncbi.nlm.nih.gov/pubmed/10861716

6. Salomon LJ, Bernard JP, Nizard J, Ville Y. First-trimester screening for fetal triploidy at 11 to 14 weeks: a role for fetal biometry. Prenat Diagn. 2005; 25: 479-483.

PubMed: https://www.ncbi.nlm.nih.gov/pubmed/15966039

7. Jauniaux E, Brown R, Rodeck C, Nicolaides KH. Prenatal diagnosis of triploidy during the second trimester of pregnancy. Obstet Gynecol. 1996; 88: 983-989.

PubMed: https://www.ncbi.nlm.nih.gov/pubmed/8942839

8. Benacerraf BR. Intrauterine Growth Retardation in the First Trimester Associated with Triploidy. J Ultrasound Med. 1988; 7: 153-154. PubMed: https://www.ncbi.nlm.nih.gov/pubmed/3280825 